\title{
PAISAGEM E IMAGEM: UMA REFLEXÃO SOBRE O ESPAÇO TURÍSTICO DE PASSA QUATRO
}

\author{
Herminia Silva Guedes*
}

\begin{abstract}
RESUMO
Este artigo apresenta uma reflexão sobre o turismo e possíveis impactos ambientais no desenvolvimento desta atividade econômica no município de Passa Quatro, estabelecendo uma relação entre imagem e paisagem, considerando a percepção do turista e do habitante do lugar.

Os conceitos de espaço, paisagem e lugar são destacados num sentido evolutivo. De espaço, como categoria filosófica e social, para paisagem, como espaço percebido, valorizado e compreendido como um sistema em constante evolução, e daí para lugar, definido como um espaço carregado de valores, vivências e significados.

Através da publicidade e fazendo uso da imagem, o turismo alimenta o imaginário das pessoas que perderam o sentido de lugar. E assim o turismo vai transformando espaços e paisagens em "lugares".
\end{abstract}

\section{APRESENTAÇÃO}

O estudo do espaço, da paisagem e do lugar, analisados à luz de critérios históricos, culturais e simbólicos vem trazendo uma valiosa contribuição, para a geografia, na compreensão das relações entre o homem e a natureza.

Os estudos ambientais, buscando entender com mais profundidade a relação homem/natureza na produção e representação do espaço, no funcionamento da paisagem e visando prognosticar o grau de transformação dos espaços, têm mergulhado fundo na pesquisa de percepção, das atitudes e dos valores de indivíduos ou grupos que habitam esses espaços.

A Geografia do Turismo, partindo de uma abordagem mais crítica para a análise dos espa- ços turísticos e das imagens que os engendram, também tem encontrado subsídios para sua pesquisa em estudos dessa natureza. O principal objetivo deste artigo é refletir sobre a formação de um espaço turístico, o papel da imagem e, no caso de Passa Quatro, levando em conta os prováveis impactos ambientais a serem causados no desenvolvimento da atividade turística neste município.

Na primeira parte, discute-se o espaço, a paisagem e o lugar enquanto um mundo vivido, percebido e experienciado. A percepção da paisagem e sua relação com o "lugar"- considerado um espaço carregado de valores e significados introduz-nos em uma abordagem metodológica tendo como suporte a fenomenologia. Num se-

(*) Pós-Graduanda - Departamento - Geografia - FFLCH/USP 
gundo momento, o entendimento do espaço turístico como uma imagem produzida pela publicidade e, na terceira parte, a apresentação do espaço turístico de Passa Quatro, abordando seu grande potencial turístico (componentes físicos e humanos) consolidado pela beleza de suas paisagens e o papel da imagem na valorização deste espaço.

\section{ESPAÇO, PAISAGEM E LUGAR}

A valorização da paisagem, a qualidade da percepção e, conseqüentemente, a interação do homem com a paisagem, a transformação do espaço em lugar, o comportamento ambiental como produto da cultura, a construção da imagem do lugar, são temas profundamente relacionados e devem ser necessariamente pesquisados para um estudo crítico do turismo.

Relph (1979) considera o espaço, a paisagem e o lugar as bases fenomenológicas que sustentam a realidade geográfica, uma vez que são experienciados no dia a dia. É o mundo vivido e experienciado como um cenário, tanto o natural como o construído pelo homem. Seu conceito de geograficidade explica a relação do ser humano com o mundo através dos espaços, paisagens e lugares, relação que inclui nossos sentimentos, conhecimentos, atitudes e comportamentos como resposta ao ambiente que vivemos.

Lowenthal (1985), Relph (1979), Collot (1986), Tuan (1980) e outros geógrafos da corrente da Geografia Humanista destacam a percepção, a conduta e o sentimento das pessoas em relação às paisagens e aos lugares e os inclui no mundo da Geografia. Para Tuan (1982) "o mundo dos fatos geográficos inclui não somente o clima, as propriedades agrícolas, os povoamentos e as nações-estados, mas também os sentimentos, os conceitos e as teorias geográficas".
Lefebvre, citado por Harvey (1993, p. 201) caracteriza três dimensões do espaço, como o vivido, o percebido e o imaginado, correspondentes respectivamente às práticas espaciais, às representações do espaço e aos espaços de representação considerados como invenções mentais (códigos, signos, "discursos espaciais", planos utópicos, paisagens imaginárias e até construções materiais como espaços simbólicos, ambientes particulares construídos, etc. ) que imaginam novos sentidos ou possibilidades para práticas espaciais.

O turismo pode se servir das representações dos espaços inferidas por meio de entrevistas com a demanda turística para captar as imagens que os turistas carregam, como frutos dos arquétipos que habitam o inconsciente e, a partir daí, criar os espaços de representação.

O espaço, como uma categoria filosófica, com um sentido mais vago na interpretação de Kant, adquire um sentido social na medida em que é derivado da experiência. É dessa forma que muitos cientistas sociais o vêem (Maldi, 1992, p. 48). Durkeim, citado por Maldi (1992, p. 45), considerou que a representação do espaço é uma perspectiva distinta do espaço enquanto representação coletiva e com isso abriu caminho para a etnografia do espaço.

Segundo Armand Frémont (1974, p. 231238), o aspecto subjetivo da pesquisa geográfica foi, durante muito tempo, desprezado pelos geógrafos, que, para fazer ciência séria, sempre consideraram espaços, regiões e paisagens como realidades objetivas: "la noction d'espace vécu trouble les perspectives habituelles des geógraphes". E foi somente nos últimos anos que alguns geógrafos franceses vêm se destacando pela contribuição de seus trabalhos dentro dessa nova visão da Geografia. Gallais (1968), Rochefort (1961, 1972), M. J. Bertrand (1972, 1973), Piveteau (1972), Metton, (1969), Claval,(1974), Rimbert, (1973), ao lado dos anglo-saxões, têm se preocu- 
pado com uma penetração mais qualitativa na metodologia geográfica. Com o nome de "espaço vivido", "espaço social", "imagem regional", "geografia da percepção", "fenomenologia do espaço", sem diferenças claramente explicitadas, essas idéias vão passando pelos meios acadêmicos, coibindo o monopólio geográfico do termo "espaço". Inegavelmente, este termo tem passado pela pena de outros especialistas de ciências humanas em trabalhos de sociologia, psicologia, filosofia, história, arquitetura e outros.

Frémont (1974, p. 231-236) atribuiu à análise das primeiras pesquisas sobre o espaço vivido uma crítica de dupla importância: 1 - crítica aos planejadores urbanos e regionais que ignoram os sonhos e realidades vividas, pelos homens, aproveitando-se para aliená-los; 2 - crítica às alusões de uma falsa ciência do "objetivo", mesmo quando essa adota, para mais credibilidade, os instrumentos de pesquisa mais aperfeiçoados da época.

Gallais (1977, p. 5-13) ao distinguir as peculiaridades do espaço vivido nas civilizações rurais tropicais estabelece uma diferença entre a concepção de espaço dessas sociedades e o das sociedades industriais. A concepção de espaço dos indivíduos das sociedades industriais enfatiza o elemento distância padronizada. Nessas sociedades o espaço é objetivado e estandardizado dimensionalmente por uma sucessão de unidades idênticas - os quilômetros. Já o espaço e o tempo das sociedades tropicais pré-industriais são descontínuos e se constituem respectivamente de lugares homogêneos e os períodos estáveis, onde as alterações sofrem um nítido retardamento e são separadas por cortes brutais, que são o fim e o começo.

Sob a influência da compartimentação sócio-étnica o espaço vivido é determinado por uma distância estrutural que não tem muita relação com a distância objetiva das sociedades industriais, podendo aumentar bruscamente o que através da distância objetiva parece insignificante. Existe a distância afetiva que reduz a distância de regiões distantes pela aproximação e conservação dos laços anímicos. O espaço também é vivido e percebido em relação a uma certa distância ecológica, onde o homem vê a natureza através de um prisma seletivo. A partir de todas estas distâncias o autor conclui que a aceitação e possibilidades de um modelo proposto dependem muito mais destas distâncias, sempre interrelacionadas, que separam cada indivíduo desse modelo, do que das vantagens econômicas objetivas. Esta análise do espaço vivido constitui, pois, um contrapeso para as visões tecnocráticas e aos novos métodos de análise espacial.

O estudo da paisagem, seja ela mais natural ou humanizada, requer uma metodologia variada. O componente humano desse sistema sente, percebe, valoriza e age em seu meio, dispondo da técnica, cada dia mais aperfeiçoada, para transformar, com uma rapidez incrível, os espaços que ocupa.

A teoria geográfica da paisagem a define, não como uma simples adição de elementos naturais e humanos, tal como o ordenamento de um inventário. A paisagem é o resultado da combinação constante de elementos físicos, biológicos e humanos e de um processo em constante evolução, sendo, ao mesmo tempo, complexa e individual. As paisagens, explica Machado (1988, p. 46), "são miríades e, constantemente, se alternam, tanto em seus componentes como em suas aparências". Tais atributos a colocam na categoria de um sistema e que, como tal, consome e produz ao mesmo tempo que é consumida e produzida.

As paisagens, no entender de Relph (1979, p. 13), são cenários significantes das experiências cotidianas e excepcionais.

A observação de uma paisagem está fisicamente condicionada pela posição do observador, pela existência de componentes não visíveis ou, 
em se tratando de percepção, para o sujeito que a observa, o significado de seus componentes, como explica Santos (1988, p. 61), tudo aquilo que vemos, que nossa visão alcança "porém sua dimensão nos é dada de acordo com aquilo que chega aos nossos sentidos, num processo seletivo de apreensão, o que torna sua percepção fisicamente deformada".

Segundo Capel (1973), alguns aspectos da paisagem atraem mais nossa atenção, outros menos e outros permanecem despercebidos, pois é o olhar humano consciente e intencional que dá origem à paisagem, e em função de nossa percepção seletiva ocorre um processo de apreciação e valorização dessa paisagem.

As sensações nos são possibilitadas pelos sentidos (visão, audição, tato, olfato), porém, é através da percepção que atribuimos um significado a estas sensações captadas pelos nossos sentidos.

A qualidade da percepção, a atribuição de significados são frutos da cultura , a qual, na forma de um conjunto de valores, técnicas e normas, se retrata na atitude do homem, em sua relação com o meio ambiente, condicionando ou afetando, portanto, o ato de experienciar a paisagem.

Tuan (1980), criador do termo topofilia - que expressa o elo afetivo entre a pessoa e o lugar, ou ambiente físico - nos fala da percepção, das atitudes e dos valores envolvidos. Segundo este geógrafo, a atitude é, primariamente, uma postura cultural. O ser humano é um organismo biológico que percebe, um ser social que tem atitude e um indivíduo único que carrega valores. $\mathrm{O}$ mesmo é válido para o grupo. São as emoções e o pensamento que dão colorido a toda experiência humana e é a experiência humana, carregada de significados que transforma um espaço em lugar.

A apreciação de uma paisagem está sempre relacionada com as lembranças, como frutos de acontecimentos marcantes. É a experiência humana que transforma um espaço em lugar.
O lugar, portanto, é considerado como um espaço vivido, carregado de significados, marcado pelas lembranças e pelo sentimento de estar em casa. Lugar é segurança. Com ele nos relacionamos afetivamente. E quanto maior o tempo vivido mais fortes serão os laços que nos unem.

Construímos o lugar da mesma forma que ele também constrói nossa identidade, com seus valores, expectativas e modo de viver, o que Dubos (1981) chamou de "espírito do lugar".

Para o geógrafo Yi-Fu Tuan, citado por Silvestre (1995, p. 61), os lugares são centros aos quais atribuímos valor. Ele observa que, freqüentemente, no decorrer de nossas experiências, o significado de espaço se funde com o de valor, o espaço anteriormente indiferenciado transforma-se em "lugar". O lugar é, portanto, um repositório de significados, que encarna experiências e aspirações humanas.

Segundo Frémont (1980, p. 132) a civilização tecnológica, ao criar espaços uniformizados como os grandes conjuntos residenciais, tem gerado relações distantes entre as pessoas e uma dissociação funcional dos lugares. O resultado dessa estandardização das construções é a perda do sentido do "lugar".

A transformação de espaços em lugares vem preencher o vazio criado na vida das grandes cidades.

As residências secundárias, os jardins, os quintais, os espaços verdes alimentam, como o turismo, o imaginário das pessoas. E é através da publicidade, fazendo o uso da imagem de um lugar, que o turismo transforma o espaço e a paisagem em um lugar.

A serra azul, glassada com nuvens brancas em dias de vento, o cheiro fresco do ar, o brilho das rochas e da vegetação, a claridade ofuscante, tudo isso misturado com o aconchego das casas antigas, das ruas silenciosas e da familiaridade 
com as pessoas, em um refúgio tranqüilo da rua, da casa ou de um quintal. Passa Quatro é um lugar, e, ainda pode ser assim...

\section{O ESPAÇO TURÍSTICO: UMA IMAGEM}

Para Miossec (1977, p. 55-68) o espaço turístico é, antes de tudo, uma imagem. Imagem formada pelos turistas e passada pelos organizadores das férias. A partir daí, explica Michaud (1983 , p. 7780) um processo de transformações formais, funcionais e significantes desse espaço se instala substituindo o espaço inicial por um meio novo, com a imagem de uma outra realidade, que se revela freqüentemente ser apenas uma miragem, se anulando à medida que o turismo invade o território.

A publicidade é um instrumento de poder no sistema capitalista. A expansão dos meios de comunicação (jornais, revistas, televisão, satélites artificiais, computadores) tem possibilitado uma divulgação, sem precedentes, de produtos e serviços de todos os lugares, para o mundo inteiro.

As técnicas de pesquisa de mercado atingiram um nível de sofisticação tamanho, onde as informações desejadas ultrapassam aquelas do nível da consciência, pois as técnicas já ousam penetrar nas profundezas do inconsciente das pessoas, desvendando os seus sonhos, conhecendo os arquétipos culturais e rastreando os símbolos que permeiam seus pensamentos, sentimentos e emoções, na construção dos significados do tempo e do espaço.

A criação dos espaços turísticos investe, portanto, na representação do espaço através da inferência dos símbolos, dos valores culturais para revestir esses espaços de visões simbólicas.

Urbain (1983, p. 115-124) afirma que a publicidade, ancorada nos interesses econômicos que a suscitam, é uma linguagem que instiga o desvendar imaginário da viagem turística. "As pes- soas sonham com países distantes. A publicidade deve converter esses sonhos em ação". A publicidade já não é apenas um convite à viagem: ela é igualmente um reflexo estilizado e verdadeiro de uma mentalidade coletiva ou de um fantasma dominante. Desta forma a semiótica do espaço pode explicar o que acontece em um espaço turístico, onde a semiótica natural sofre transformações, a partir da intervenção das semióticas artificiais ou humanas.

O conteúdo simbólico das paisagens é utilizado pela propaganda na produção das imagens para ser vendido aos turistas. São imagens que os convidam para lugares mais distantes, mais exóticos, perseguindo sempre seus sonhos mais secretos.

O historiador Jacques Le Goff, citado por Maldi (1993, p. 44-63) escreveu um ensaio sobre a representação do espaço, analisando a relação entre o ambiente e a religião. Na sua história, inspirada em antropologia, destaca o deserto como uma realidade, ao mesmo tempo, geográfica-histórica e simbólica para os modelos culturais do ocidente medieval, derivados da Bíblia.

"O mesmo, segundo Le Goff, se sucedeu à floresta: à tradição judaica e oriental do deserto veio juntar-se a tradição céltica e também germânica e escandinava da floresta-deserto, um lugar de solidão" (citado por Maldi, 1993, p. 54).

Na floresta, o natural, o mistério, o isolamento, o sagrado podem estar reunidos. A atração ou repulsão por este ambiente podem estar obviamente ligados a seu simbolismo cultural, à educação ambiental ou às experiências vividas. No entanto, o despertar para a sua preservação, a apreciação de sua beleza, a necessidade de ter um contato mais íntimo com esta realidade geográfica podem ser suscitados também pela publicidade através de uma imagem.

Miossec (1977, p. 55-68) distingue três tipos de imagem turística: a imagem global, cor- 
respondente às aspirações profundas, aos arquétipos que ultrapassam o comportamento regional ou nacional e corresponde a imperativos biológicos territoriais do homem; a imagem atual, que corresponde ao espaço criado pela moda, pelos cânones contemporâneos da beleza para a sociedade atual; e a imagem tradicional, profunda, fixada lentamente durante os séculos e a cultura dos turistas, lhes permitem, com isso, saborear toda sua riqueza.

Da imagem global extrai-se o sentimento que as pessoas têm de evadir-se do lugar onde vivem. Na imagem e no comportamento há ambivalência, contradição e duplo movimento entre o real e o imaginário, o imaginário e o real. A mudança do ambiente deve acontecer com segurança. A surpresa não tem sentido apenas pela originalidade do novo ambiente. É preciso levar em conta a compreensão da mensagem, da imagem, em função da subjetividade do grupo ou do indivíduo. Por isso a informação não pode ser nem muito banal e nem muito original (Miossec, 1977, p. 55-68).

Desta forma, o turismo, mediado pela propaganda, atendendo às necessidades e aos ditames culturais (símbolos, valores, mitos) dos turistas e aos interesses econômicos dos agentes de turismo, vai invadindo os lugares. Num processo de criação e destruição de imagens e paisagens substitui os costumes locais por outros.

Silvestre (1995), analisando o caso de São Lourenço e seu crescimento vertical, levantou questões que, há muito, vêm incomodando não apenas alguns especialistas de turismo, mas até mesmo cidadãos dessa cidade e da região, que assistem ou acompanham, perplexos, à construção desenfreada dos altos edifícios.

As paisagens vêm passando por rápidas transformações deixando para trás, num passado ainda muito recente, a nossa convivência com uma cidade bucólica, em alguns pontos bem próxima de uma beleza natural.

A partir do baixo interesse dos turistas de São Lourenço pela crenoterapia, (tratamento com águas minerais) constatado pela pesquisa e da descaracterização de sua paisagem, como se explica ainda um fluxo turístico aparentemente estável nessa estância? O que leva os turistas para lá? Seria a eficiência da propaganda na imagem do lugar? Ou as ligações religiosas ou místicas com as diferentes religiões ou correntes filosóficas espiritualistas que ainda lá existem?

Buscando entender a permanência do turismo e a caracterização da demanda turística de São Lourenço, V. Silvestre (1995) entrevistou, durante um ano, em épocas diferentes, 556 turistas.

O resultado desse trabalho, acompanhado por uma rica fundamentação teórica, pôde responder parte de nossas indagações quando a autora, encaminhando as conclusões, escreve: "no caso de São Lourenço, o sujeito é o turista que, através da percepção, suas vontades, necessidades, emoções, sentimentos e afetividades interage com o lugar e suas paisagens. Dessa forma, a percepção da paisagem faz parte da experiência dos indivíduos em relação aos lugares. Inclui experiências passadas e é através delas que o turista atribui significados e valores à paisagem de São Lourenço" (Silvestre, 1995, p. 62).

Neste processo, explica Michaud (1983, p. 77-80), as qualidades autênticas da região são alteradas ou destruídas e a zona turística assume um caráter neutro, banalizado. O desaparecimento destes caracteres é compensado pela criação de um sistema de símbolos expressando o "típi$\mathrm{co}^{\prime \prime} \mathrm{e}$, tentando reconstituir a diferença, a arquitetura turística tenta dissimular sua banalidade através de uma rede de elementos baseados na arquitetura tradicional, enquanto certas características culturais, reduzidas a clichês, substituem 
a riqueza de costumes e de um modo de vida desaparecidos.

\section{O ESPAÇO TURÍSTICO DE PASSA QUATRO}

Passa Quatro faz parte do Circuito das Águas do sul de Minas, região estratégica pela riqueza de seus recursos hídricos e pela beleza de suas paisagens serranas.

O modelo de São Lourenço e a proximidade das duas cidades, a situação geográfica do município, localizado a $240 \mathrm{Km}$ de São Paulo e $230 \mathrm{Km}$ do Rio de Janeiro e o incremento do turismo após a construção do Hotel Recanto das Hortências justificam nossas crescentes preocupações quanto aos rumos a serem tomados pela atividade turística na cidade de Passa Quatro.

A ausência de uma política de turismo aliada a outros fatores de ocorrência local coloca uma reflexão maior sobre as inevitáveis transformações dessas paisagens e seus possíveis impactos ambientais sobre o meio natural. Tais preocupações suscitam as seguintes perguntas:

- Como os turistas percebem e vivenciam essas paisagens?

- Até que ponto a imagem, a percepção, os gostos e preferências dos turistas podem contribuir para grandes alterações nessas paisagens?

- O turismo satisfaz apenas às expectativas do empresariado local ou da população residente como um todo?

- Que tipo de turismo interessa mais aos moradores?

-Qual é o turismo mais adequado para este município, dotado de grandes potencialidades naturais ao lado de grandes fragilidades ambientais?

\subsection{Os componentes da paisagem}

Passa Quatro ocupa uma área de $312 \mathrm{~km}^{2}$, com uma população de aproximadamente 13.730 habitantes, sendo 9.062 da zona urbana e 4.668 da zona rural (Censo Demográfico de 1991).

Localizado na região da Mantiqueira, o município apresenta-se com um conjunto montanhoso de vertentes íngremes e vales encaixados, bastante susceptíveis a deslizamentos gravitacionais e formação de ravinamentos. Sua sede encontra-se a uma altitude de $915 \mathrm{~m}$.

Ao longo do vale, observam-se formas de colinas com vertentes suaves e vales de fundo amplo. Possui, portanto, uma variedade de paisagens que o coloca entre as altitudes da planície do fundo do vale até fortes elevações com mais de $2.000 \mathrm{~m}$ de altitude. Dentre os doze picos mais elevados do país, cinco se localizam em Passa Quatro: Pico do Itaguaré ( $2.308 \mathrm{~m}$ ), Marins (2.422 m), Pico da Gomeira (2.068 m), Pico do Capim Amarelo (2.392 m) e Pedra da Mina $(2.770 \mathrm{~m})$. O mais conhecido é o Itaguaré, pois, de lá se avista boa parte do Vale do Paraíba.

A rede de drenagem do município é bastante densa e faz parte da Bacia do Rio Verde, a qual, por sua vez, pertence à Bacia do Rio Grande (em direção sul-norte ).

O clima, conforme estudos da Fundação João Pinheiro (1973), classifica-se pela tipologia de Köppen como Cwb (Tropical de altitude com verões suaves), sendo as médias máximas e mínimas, respectivamente, $25^{\circ} \mathrm{C}$ e $13^{\circ} \mathrm{C}$. O relevo serrano exerce grande influência na temperatura, podendo, no inverno, registrar temperaturas mínimas absolutas inferiores a $0{ }^{\circ} \mathrm{C}$, conforme registros da Estação Auxiliar de Passa Quatro, pertencente ao $5^{\circ}$ distrito do Instituto Nacional de Meteorologia.

A formação vegetal original é a Floresta Tropical Subcaducifólia, com a presença marcante das 
araucárias, sobretudo em altitudes acima de 1.000 $m$. Hoje a vegetação original encontra-se, em grande parte, substituída por pastagens havendo ocorrência de reflorestamentos de eucaliptos, no altos da serra, a sudoeste do município.

Na economia de Passa Quatro, a agropecuária tem sua expressão na produção de leite, hortigranjeiros, ao lado da agricultura de batata e de frutas temperadas (ameixa, pêra, pêssego). Porém é o setor industrial o que mais contribui com a arrecadação do ICM (IBGE, 1979). As principais indústrias são: de papel para embalagens, de água mineral, de laticínios, de guaraná (refrigerante), de confecções e forjaria.

O turismo vem ganhando espaço na economia do município, com maior intensidade, a partir da década de 80 . Seu desenvolvimento parece ser do interesse não apenas do empresariado local, mas de boa parcela da população que vê com bons olhos esta opção econômica para o progresso da cidade.

Pelo valor de suas águas minerais e de sua água potável que abastecia abundantemente a cidade, pela sua situação geográfica, no vértice do triângulo Rio - São Paulo e, sobretudo pelo clima agradável e saudável, Passa Quatro foi reconhecida como estância hidromineral, pela Lei Estadual n²5524 de 16.09.1974.

\subsection{A imagem de Passa Quatro}

Auguste Saint Hilaire, naturalista suíço, em suas viagens pelo Brasil, com o objetivo de conhecer nossa flora, fauna e costumes, esteve em Passa Quatro, em 14 de março de 1823, e assim se expressou em seu relatório:

\footnotetext{
"Desde que viajo na Capitânia de Minas, talvez nada visse de mais belo do que a região hoje atravessada. Seguimos um vale bastante largo, cercado de mon-
}

tanhas pitorescas e coberto de árvores, no meio das quais se destaca sempre a majestosa araucária. Este vale é regado por um rio que dá mil voltas e pelo qual passa quatro vezes para chegar aqui, donde lhe vem o nome Passa Quatro. Suas margens apresentam, alternadamente, pastos, capões de mato pouco elevados, terrenos cultivados, entre os quais se vêem, de distância em distância, grupo de pinheiros. Pequenas casas ainda acrescentam nova variedade à paisagem. À nossa frente, tínhamos a Serra da Mantiqueira, a cujos cumes, bastante diferentes pelo formato, veste sombria floresta. Nada melhor lembra os vales da Suíça do que este que acabo de fazer a descrição".

As paisagens se humanizam, envelhecem ou se renovam, porém a imagem de sua beleza parece permanecer eterna na memória dos habitantes do lugar, da mesma forma que as narrativas dos viajantes evocam sempre uma imagem viva embora esta já se diferencie muito da imagem atual.

A imagem da grande floresta verde, da limpidez das águas correntes e o cheiro de mato no ar acabam sempre passados consciente ou inconscientemente aos visitantes, pelos moradores, que estabeleceram, durante muitos anos, um elo afetivo, com as paisagens do lugar.

Com o intuito de se conhecer a imagem que o turista tem da cidade, sua percepção do espaço e suas sugestões ou críticas em relação aos equipamentos turísticos entrevistou-se um total de 103 visitantes.

As entrevistas aconteceram no período de fins de julho de 1996 a meados de abril de 1997, abrangendo alta e baixa temporada, feriados e finais de semana prolongados.

Para facilitar o trabalho na apreensão da imagem, da percepção e na coleta de sugestões para melhoria do turismo de Passa Quatro, optou-se por abordar, preferencialmente, os visitantes com mais de 20 anos. 
Esses entrevistados encontravam-se hospedados em hotéis e pousadas de diferentes níveis, casa de familiares e amigos.

Sendo o enfoque maior da pesquisa o aspecto psicológico em relação à imagem produzida pela publicidade ou por amigos e familiares e seus efeitos na percepção e comportamento dos turistas, não foi inquirida a renda mensal dos indivíduos embora saibamos que o nível de renda seja imprescindível para uma análise de demanda.

Para analisar os itens propostos anteriormente iniciou-se o trabalho com a identificação da população pela procedência, sexo, idade, profissão, escolaridade e número de visitas à cidade. E logo, após, foram colocadas as seguintes questões:

- De que forma obteve informações sobre Passa Quatro?

- Qual é a imagem que você tem de Passa Quatro?

- Esta imagem atual corresponde àquela criada/ divulgada pela propaganda?

- O que mais lhe atrai nesta cidade?

- O que não gostou?

- O que precisa ser melhorado em nossa cidade? (apresentar 3 sugestões enumerando-as conforme o grau de importância.)

O procedimento aleatório da pesquisa em relação à escolha dos entrevistados nos hotéis, nas pousadas, nas ruas, em casas de comércio produziu a seguinte distribuição de estrutura etária:
Tabela 1 - Estrutura Etária da População Entrevistada

\begin{tabular}{l|c}
\hline IDADES & No DE TURISTAS \\
\hline 10 a 20 anos & 9 \\
21 a 30 anos & 18 \\
31 a 40 anos & 33 \\
41 a 50 anos & 23 \\
51 a 60 anos & 6 \\
61 a 70 anos & 10 \\
mais de 70 anos & 4 \\
\hline TOTAL: & 103 \\
\hline
\end{tabular}

Observando a tabela 1 constata-se que 50\% dos entrevistados encontram-se na faixa de 31 a 50 anos, sendo, no total de 103, 56 do sexo masculino e 47 do sexo feminino.

Em relação à procedência, conforme os dados da tabela 2, fica evidente o predomínio do Estado de São Paulo como grande emissor, numa faixa de, aproximadamente, $60 \%$ dos entrevistados.

Tabela 2 - Procedência

\begin{tabular}{l|c}
\hline \multicolumn{1}{c|}{ CIDADE } & N $^{\circ}$ TURISTAS \\
\hline Grande São Paulo & 41 \\
Vale do Paraíba & 13 \\
Outras cidades paulistas & 7 \\
Grande Rio de Janeiro & 23 \\
Outras cidades fluminenses & 6 \\
Belo Horizonte & 6 \\
Uberlândia & 2 \\
Juiz de Fora & 5 \\
\hline TOTAL & 103 \\
\hline
\end{tabular}

O grau de escolaridade da clientela entrevistada aponta o predomínio (pouco mais de $50 \%$ ) de pessoas com instrução de nível superior. 
Tabela 3 - Escolaridade

\begin{tabular}{l|c}
\hline GRAU DE ESCOLARIDADE & $\mathrm{N}^{\circ}$ TURISTAS \\
\hline $1^{\circ}$ grau incompleto & 5 \\
$1^{\circ}$ grau completo & 10 \\
$2^{\circ}$ grau incompleto & 6 \\
$2^{\circ}$ grau completo & 3 \\
Superior incompleto & 3 \\
Superior completo & 53 \\
\hline
\end{tabular}

Dentre as profissões que obtiveram a maior freqüência conforme o quadro da tabela 4 , destacam-se em ordem decrescente: comerciantes, professores e advogados.

Tabela 4 - Ocupação

\begin{tabular}{l|c}
\hline OCUPAÇÃO & TURISTAS \\
\hline NÃO ATIVOS & 7 \\
Estudantes & 5 \\
Prendas Domésticas & 2 \\
Aposentados & 14 \\
TOTAL & \\
ATIVOS & \\
Comerciários, gerente & \\
de vendas de importação & 8 \\
e representação comercial & 15 \\
Comerciantes & 2 \\
Industriários & 3 \\
Secretários & 3 \\
Bancários & 13 \\
Professores & 8 \\
Advogados & \\
Publicitário e Profissional & 3 \\
de Turismo & 27 \\
Outros & 82 \\
\hline TOTAL &
\end{tabular}

Neste trabalho procurou-se identificar também os turistas em relação ao número de visitas já feitas e as formas pelas quais obtiveram informações sobre a cidade de Passa Quatro. Verificou-se que $41 \%$ dos entrevistados eram novatos, ou seja, visitavam a cidade pela primeira vez, e apenas $20 \%$ já o haviam feito inúmeras vezes. E, quanto às formas de informação, constatou-se que $50 \%$ dos turistas se serviram de informações de familiares e amigos e, os outros $50 \%$ restantes, por intermédio de folders $(9 \%)$, jornais (7\%), e os demais, de formas variadas, como através de agência de turismo, televisão (pesca da truta), convênio no trabalho, Guia 4 Rodas e outras. Donde se conclui que a publicidade ou a divulgação comercial da cidade ainda concorre em desvantagem com a propaganda caseira dos familiares ou amigos dos familiares.

Dentre todas as questões constantes no questionário da entrevista a de maior importância para este estudo é a questão $n^{\circ} 3$ : Qual é a imagem que você tem de Passa Quatro?

As respostas mais usadas para expressar a imagem solicitada, bem como freqüência destas respostas, estão expostas na tabela 5 . 
Tabela 5 - Expressões mais usadas pelos turistas para explicar a imagem que carregam de Passa Quatro:

\begin{tabular}{l|c}
\hline EXPRESSÕES & No VEZES $^{\text {Cidade calma }}$ \\
e tranqüila & 32 \\
Clima bom & 24 \\
Povo hospitaleiro & 23 \\
Cidade para descanso & 16 \\
Paisagem & 14 \\
Belezas naturais & 14 \\
Cidade bonita & 13 \\
Cidade pacata & 10 \\
Cidade de montanhas & 10 \\
Cidade acolhedora & 9 \\
Cidade hospitaleira & 8 \\
Ar puro & 7 \\
Cidade aconchegante & 7 \\
Pesca de truta & 6 \\
Cidade bucólica & 4 \\
\hline
\end{tabular}

Se agruparmos as expressões mais freqüentes em torno de dois pontos de atração, natureza e povo, chegaremos ao resultado da tabela 6:

Tabela 6 - Pontos de atração do turista

\begin{tabular}{|c|c|c|c|}
\hline \multicolumn{2}{|c|}{ NATUREZA } & \multicolumn{2}{|l|}{ POVO } \\
\hline Clima & 24 & Povo hospitaleiro & 23 \\
\hline Paisagens & 14 & Cidade hospitaleira & 8 \\
\hline Belezas & & Cidade calma e & \\
\hline Naturais & 14 & tranqüila & 32 \\
\hline Cidade das & & & \\
\hline Montanhas & 10 & & \\
\hline Ar puro & 7 & & \\
\hline $\begin{array}{l}\text { Pesca da } \\
\text { truta }\end{array}$ & 6 & & \\
\hline TOTAL & 75 & TOTAL & 63 \\
\hline
\end{tabular}

Com este quadro pode-se confirmar, em parte, a valorização de Passa Quatro pela beleza de suas paisagens e pelo aconchego do "lugar" onde as relações entre turistas e moradores parecem mais próximas, propiciando a criação de laços afetivos e momentos vividos cada vez mais cheios de significados.

Ainda em relação à imagem é importante ressaltar que $74 \%$ dos entrevistados afirmaram a permanência da imagem criada pela informação após o contato com a realidade, e de $10 \%$ do total admitem a não existência de uma anterior por falta de conhecimento ou divulgação da cidade.

Quando inquiridos sobre o que mais gostam na cidade os turistas apontaram prioritariamente o clima (com maior freqüência), a natureza, a tranqüilidade e a hospitalidade do povo.

Rastrearam-se também as principais queixas do turista. Quando questionados sobre o que não gostaram na cidade as reclamações incidiram sobre a falta de placas com informações de pontos turísticos, sujeira nas ruas, precariedade das estradas, falta de lazer, falta de telefones públicos, falta de opções para refeições. Seguiram-se também observações em torno da falta de bancos nas praças, manutenção das praças, pouca opção para compra de artesanatos e doces, falta de banheiros públicos, poluição dos rios, poluição sonora dos carros de propaganda e a falta de incentivo à cultura e sua conexão com o turismo.

Insistindo na afirmação que a qualidade da percepção e atribuição de significados do ambiente que nos cerca são frutos da cultura, a qual também pode ser retratada na atitude do homem em relação ao meio ambiente, fundamentamos nossas conclusões e arriscamos timidamente a traçar um perfil da demanda turística de Passa Quatro.

Não há mais dúvida que o potencial turístico da cidade no tocante às belezas naturais é reconhecido até pelos mais desinteressados. A 
imagem que se cria e se passa permanece, pelo menos essencialmente, a mesma. Mas os canais pelos quais passa são diferentes, da mesma forma que diferem os níveis de percepção das pessoas. Os valores existem e filtram a percepção, da mesma forma que determinam os comportamentos e criam necessidades. Se assim não fosse, diríamos que todos os turistas de Passa Quatro, com exceção daqueles dotados de forte espírito de destruição, tenderiam a elaborar juízos, perceber detalhes, apontar sugestões e a agir cada vez mais em prol da conservação ou preservação da natureza, já que a imagem sustentada pela propaganda tem suas bases nos encantos que a natureza oferece aos nossos olhos - a beleza das paisagens e a vitalidade que promete à nossa saúde. Contudo, uma certa incoerência em relação às prioridades é objetivamente detectada, logo que se realiza uma enquete sobre as sugestões para melhoria do espaço turístico.

Tabela 7 - O que precisa ser melhorado em Passa Quatro

\begin{tabular}{l|c}
\hline SUGESTÕES & No VEZES (freqüência) $^{\text {Placas com sinalização }}$ \\
divulgando locais turísticos & 13 \\
Sinalização nas ruas e estradas & 6 \\
Conservação das ruas e & \\
pavimentação & 10 \\
Mais áreas de lazer & 15 \\
Melhoria no comércio com & 11 \\
mais opções de compra & \\
Visual e melhoria da infra & 4 \\
-estrutura & \\
Funcionamento da linha & 5 \\
ferroviária & \\
Diversão para crianças: parque & \\
infantil e outras &
\end{tabular}

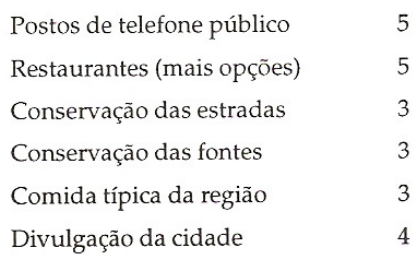

As sugestões para melhoria do turismo, como mostra a tabela 7, são condizentes, em sua maioria, com as reclamações dadas anteriomente. Observa-se que não há grande insistência naqueles aspectos ligados à conservação da paisagem.

A falta de "cultura turística" das pessoas que viajam, afirma Doris Ruschmann (1997, p. 10), faz com que elas se comportem de forma alienada em relação ao meio em que vivem e se abstenham de responsabilidade na preservação e na originalidade da destinação.

\subsection{Conclusão}

O turista é, antes de tudo um consumidor consumidor de natureza ou de paisagens. Sua presença sinaliza, para a maioria dos residentes, uma possibilidade de melhoria na qualidade de vida na cidade, sem, contudo, estar esta qualidade de vida comprometida com uma qualidade ambiental.

Num julgamento de valor da atividade turística, entendendo a qualidade de vida como uma melhoria da receita financeira e do padrão de vida de uma parcela maior da população, pode-se considerar o turista, simplesmente, como um destruidor/criador da paisagem, ou mero transformador neste fenômeno, sempre aceito, pacificamente, pelos moradores do lugar.

Contudo, numa análise procedente de uma visão mais holística, ou que leva em conta o econômico e o ecológico de espaço, da paisagem e do lugar, há que se considerar que, no manejo da 
atividade turística, pouca ou nenhuma atenção tem sido dada ao seu subproduto - a degradação ambiental.

A publicidade, aliada aos interesses empresariais e do governo, deve agir conjunta e objetivamente no sentido de aumentar cada vez mais o número de consumidores do turismo, expandindo essa atividade com a geração de mais oferta, circulação e acumulação dos capitais.

Nos espaços turísticos dotados de mais natureza, uma dialética problemática pode se estebelecer na abertura de estradas ou caminhos que conduzem aos "recantos". Na maioria das vezes, uma engenharia a serviço da indústria do turismo e, logicamente, comprometida com práticas imediatistas para afluência rápida dos capitais, procura, evidentemente, ignorar os problemas ambientais, permanecendo na superficialidade.

Sem o conhecimento mais profundo do relevo e de seus processos, os técnicos dão permissão para uma construtora rasgar os morros, enxugar os brejos, desviar os córregos, executando-se, dessa forma, com a autorização do governo e do povo, as obras que trarão o "progresso" para a cidade.

Outros impactos ambientais podem ocorrer com o incremento do turismo. A poluição dos rios tem seu nível aumentado em função de sobrecarga da rede de esgotos; a poluição dos solos urbanos e rurais, pelo aumento do lixo, e; a poluição sonora e do ar, pelo crescimento do número de veículos e de carros de som nas ruas. Em outras palavras, se instala na paisagem a síndrome de uma urbanização acelerada e sem planejamento, tão comum aos países do Terceiro Mundo.

A cobertura vegetal, seja ela primária ou secundária, ainda presente junto às sedes dos pequenos municípios desprovidos de um órgão de poder para as questões ambientais, vai cedendo, gradativamente, seus espaços para a amplia- ção dos equipamentos turísticos, das residências secundárias e dos bairros residenciais periféricos.

Na cidade de Passa Quatro, onde o conforto térmico foi apontado pelos turistas como um ponto alto da procura, a manutenção e o aumento das áreas verdes, principalmente daquelas compostas por árvores de sombra, deveriam constituir motivo de preocupação ou prioridade em qualquer projeto paisagístico. Só assim, o clima local, embora sujeito às influências das mudanças climáticas globais, poderia sustentar as suas temperaturas amenas no verão.

A grande valorização dos aspectos econômicos do turismo, com projetos de curto prazo, buscando soluções rápidas para os problemas econômicos locais, tem deixado de lado uma reflexão mais profunda sobre os aspectos relacionados ao meio natural, no que tange à sua capacidade física e fragilidades, à cultura e à população residente. Daí a importância fundamental de um planejamento turístico que tente harmonizar os recursos físicos, culturais e sociais de qualquer lugar receptor.

Este pequeno trabalho pode ter dado início à pesquisa do turismo em Passa Quatro. Um aprofundamento dos aspectos aqui abordados será possível mediante pesquisas posteriores, destinadas a uma análise ou ao planejamento de um turismo mais saudável para a cidade e região das águas. 


\section{BIBLIOGRAFIA}

CAPEL, H. Percepción del medio y comportamiento geográfico. Revista de Geografia, Barcelona, n. 1-2, 1973, p. 55150

COLLOT, M. Points de vue sur la Perception des Paysages. L'Espace Géographique n. 3, 1986, p. 211-217

DUBOS, R. Namorando a Terra. São Paulo, Edusp, 1981.

FRÉMONT, A. Recherches sur l'espace vécu. L'Espace Géographique n. 3, 1974, p. 231-238

. A região - espaço vivido. Coimbra, Almedina, 1980.

FUNDAÇÃO JOÃO PINHEIRO. Estudos dos Recursos Naturais - Município de Passa Quatro - MG, Belo Horizonte, 1973.

GALLAIS, J. Alguns aspectos do espaço vivido nas civilizações do mundo tropical. Boletim Geográfico, Rio de Janeiro, (35) 254, p. 5-13, 1977.

HARVEY, D. Condição Pós-Moderna. Uma pesquisa sobre as Origens da Mudança Cultural. São Paulo, Loyola, 1993.

INSTITUTO BRASILEIRO DE GEOGRAFIA E ESTATÍSTICA IBGE. Anuário Estatístico. 1979.

LOWENTHAL, D. Geografia, experiência e imaginação: em direção a uma epistemologia geográfica. In: CHRISTOFOLETTI, Antonio. (org.) Perspectivas da Geografia. São Paulo, Difel, 1985.

MACHADO, L. M. C. P. A Serra do Mar Paulista: um estudo de paisagem valorizada. Tese de Doutoramento em Geografia, Instituto de Geociências e Ciências Exatas, UNESP, Campus de Rio Claro, 1988.
MALDI, D. Pantanais, Planícies, Sertões: uma reflexão antropológica sobre espaços brasileiros. Boletim Paulista de Geografia, São Paulo, n. 71, 1993, p. 41-63

MICHAUD, J-Luc. Le tourisme face à l'environnement. Paris. Presses Universitaires de France, 1983.

MIOSSEC, J. M. L'image touristique comme introduction à la Geographie du Tourisme. Annales de Geographie, Paris. v. 58 (773), p. 55-68, jan/fev., 1977.

RELPH, E. C. As bases fenomenológicas da Geografia. Geografia, Rio Claro, v. 4, n. 7, 1979, p.1-25

SAINT-HILAIRE, A. Segunda Viagem do Rio de Janeiro à Minas Gerais e São Paulo. Editora Nacional, 1938.

SANTOS, M. Metamorfoses do espaço habitado. São Paulo, Hucitec, 1988.

SILVESTRE, V. Enfoque Geográfico de um Espaço Turístico. Um olhar sobre São Lourenço. Dissertação de Mestrado em Geografia Humana, Faculdade de Filosofia, Letras e Ciências Humanas, USP, São Paulo, 1995.

TUAN, Yi-Fu. Topofilia. Um estudo da percepção, atitudes e valores do meio ambiente. São Paulo, Difel, 1980.

. Espaço \& Lugar. As perspectivas da experiência. São Paulo, Difel, 1985.

URBAIN, J. D. Sur l'espace du touriste: un voyage em Tunisie. Éléments pour une sémiotique de l'espace touristique des Français. L'Espace Geographique, Paris, v. 2,1983 , p. 115-124. 